Supplementary Information

\title{
Room Temperature Batch and Continuous Flow Synthesis of Water-Stable Covalent Organic Frameworks (COFs)
}

Yongwu Peng, ${ }^{\text {a, }}$ Wai Kuan Wong,,${ }^{\text {a }}$ Z Zhigang Hu, ${ }^{\text {a }}$ Youdong Cheng, ${ }^{a}$ Daqiang Yuan, ${ }^{\mathrm{b}}$ Saif A. Khan, ${ }^{\text {a, }}$ and Dan Zhao ${ }^{\mathrm{a},{ }^{*}}$

${ }^{a}$ Department of Chemical \& Biomolecular Engineering, National University of Singapore, 4 Engineering Drive 4, 117585 Singapore

${ }^{\mathrm{b}}$ State Key Laboratory of Structural Chemistry, Fujian Institute of Research on the Structure of Matter, Chinese Academy of Sciences, Fuzhou, 350002 China

${ }^{\dagger}$ These authors contributed equally to this work.

Correspondence and requests for materials should be addressed to D.Z. (E-mail: chezhao@nus.edu.sg) or S.A.K (Email: chesakk@nus.edu.sg). 


\section{Experimental Details}

Synthesis of TpPa-1 using room temperature solution-dispersion approach

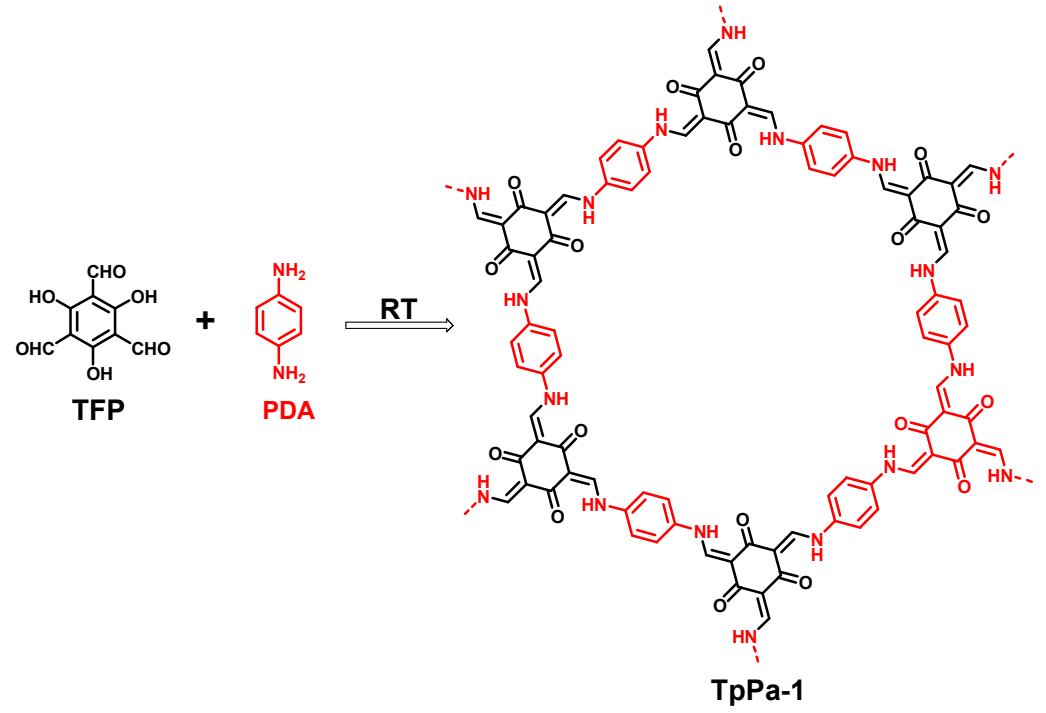

A $10 \mathrm{~mL}$ glass vial was charged with 1,3,5-triformylphloroglucinol (TFP) (42 mg, $0.2 \mathrm{mmol}$ ) and dioxane $(1 \mathrm{~mL})$. The mixture was sonicated for $10 \mathrm{~min}$ to get a homogenous dispersion. Afterwards, $p$-phenylenediamine (PDA) $(32 \mathrm{mg}, 0.3 \mathrm{mmol})$ in $1 \mathrm{~mL}$ of dioxane solution was added, and the resultant suspension was briefly sonicated for $1 \mathrm{~min}$. Subsequently, acetic acid ( $3 \mathrm{M}, 0.35 \mathrm{~mL}$ ) was added and the vial was then sealed and left undisturbed for 3 days at room temperature. The yielded red precipitate was collected by centrifugation and washed with anhydrous tetrahydrofuran, anhydrous acetone, and anhydrous dichloromethane, separately. The collected powder was then activated by solvent exchange with anhydrous methanol for 3 times and dried at $120{ }^{\circ} \mathrm{C}$ under vacuum for $12 \mathrm{~h}$ to give a red powder with $80 \%$ isolated yield and a molecular formula of $\left(\mathrm{C}_{18} \mathrm{H}_{12} \mathrm{~N}_{3} \mathrm{O}_{3}\right)_{\mathrm{n}}(\%$ calc/found: $\mathrm{C} 69.5 / 66.5, \mathrm{H}$ 3.47/3.28, N 13.87/12.92).

\section{Synthesis of $\mathrm{N}_{3}$-COF using room temperature solution-dispersion approach}

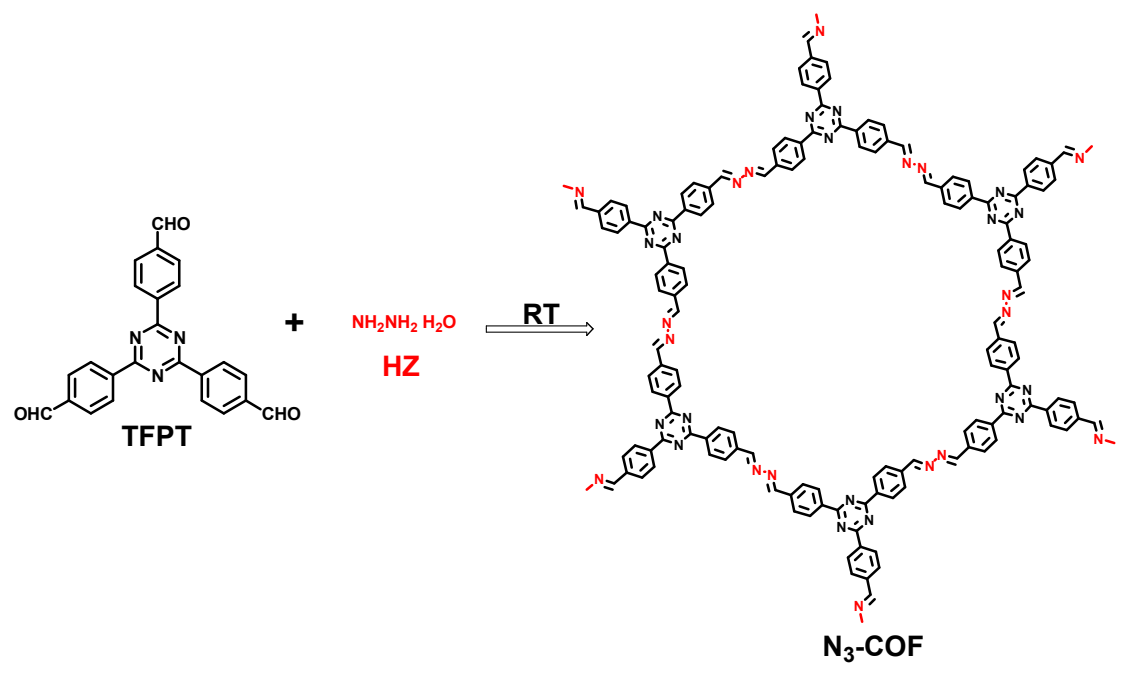


A $10 \mathrm{~mL}$ glass vial was charged with 1,3,5-tris-(4-formyl-phenyl)triazine (TFPT) (33 mg, $0.08 \mathrm{mmol})$ and 1,2-dichlorobenzene/ethanol $(2: 3 \mathrm{v} / \mathrm{v}, 2 \mathrm{~mL})$. The mixture was sonicated for $10 \mathrm{~min}$ to get a homogenous dispersion. Afterwards, hydrazine $(6.5 \mathrm{uL}, 0.12 \mathrm{mmol})$ was added and the resultant suspension was sonicated briefly for 10-20 s. Subsequently, acetic acid $(6 \mathrm{M}, 0.2 \mathrm{~mL})$ was added and the vial was then sealed and left undisturbed for 3 days at room temperature. The yielded yellow precipitate was collected by centrifugation and washed with anhydrous tetrahydrofuran, anhydrous acetone, and anhydrous dichloromethane, separately. The collected powder was then activated by solvent exchange with anhydrous methanol for 3 times and dried at $120^{\circ} \mathrm{C}$ under vacuum for $12 \mathrm{~h}$ to give a yellow powder with $85 \%$ isolated yield and a molecular formula of $\left(\mathrm{C}_{24} \mathrm{H}_{15} \mathrm{~N}_{6}\right)_{\mathrm{n}}(\%$ calc/found: $\mathrm{C} 74.40 / 72.62, \mathrm{H}$ $3.90 / 3.08, \mathrm{~N} 21.69 / 21.21$ ).

\section{Synthesis of TFPB-HZ using room temperature solution-dispersion approach}

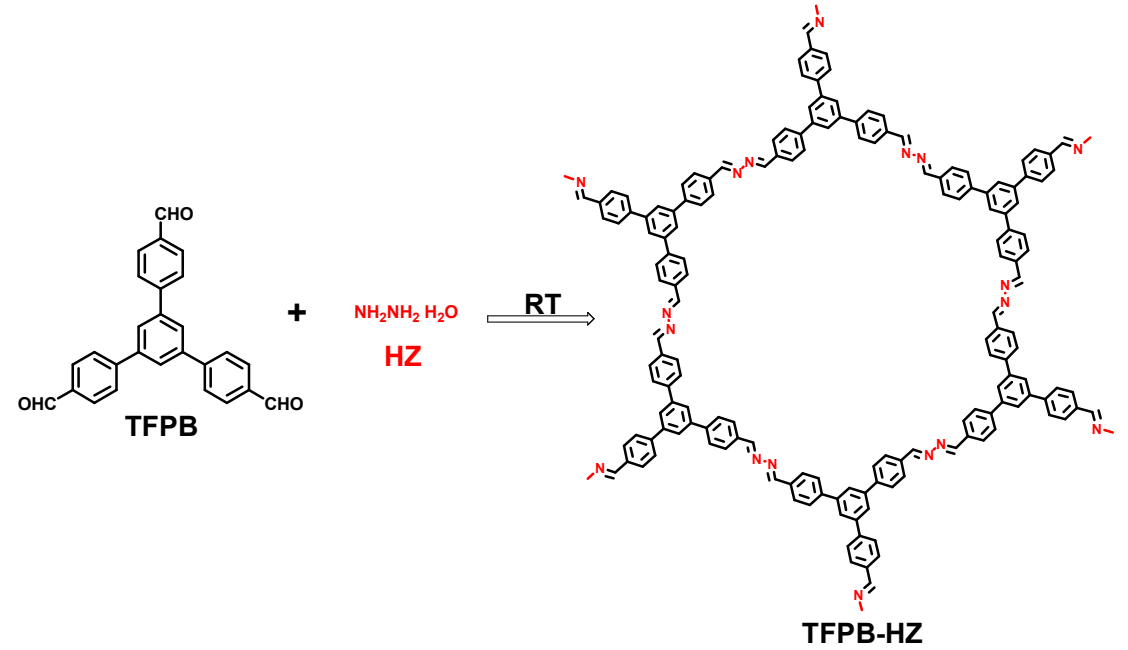

A $10 \mathrm{~mL}$ glass vial was charged with 1,3,5-tris-(4-formyl-phenyl)benzene (TFPB) (33 $\mathrm{mg}$, $0.08 \mathrm{mmol})$ and 1,2-dichlorobenzene/ethanol $(2: 3 \mathrm{v} / \mathrm{v}, 2 \mathrm{~mL})$. The mixture was sonicated for $10 \mathrm{~min}$ to get a homogenous dispersion. Afterwards, hydrazine $(6.5 \mathrm{uL}, 0.12 \mathrm{mmol})$ was added and the resultant suspension was sonicated briefly for 10-20 s. Subsequently, acetic acid $(6 \mathrm{M}, 0.2 \mathrm{~mL}$ ) was added and the vial was then sealed and left undisturbed for 3 days at room temperature. The yielded yellow precipitate was collected by centrifugation and washed with anhydrous tetrahydrofuran, anhydrous acetone, and anhydrous dichloromethane, separately. The collected powder was then activated by solvent exchange with anhydrous methanol for 3 times and dried at $120{ }^{\circ} \mathrm{C}$ under vacuum for $12 \mathrm{~h}$ to give a pale yellow powder with $82 \%$ isolated yield and a molecular formula of $\left(\mathrm{C}_{27} \mathrm{H}_{15} \mathrm{~N}_{3}\right)_{\mathrm{n}}(\%$ calc/found: $\mathrm{C} 85.02 / 85.65$, H 3.96/3.86, N 11.02/10.50).

\section{Synthesis of TFB-HZ using room temperature solution-dispersion approach}




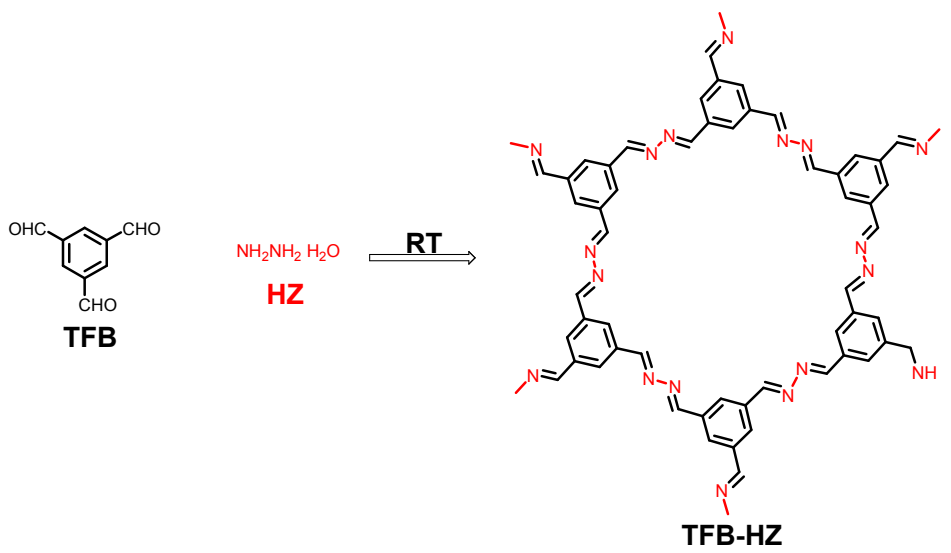

A $10 \mathrm{~mL}$ glass vial was charged with 1,3,5-triformylbenzene (TFB) $(16 \mathrm{mg}, 0.1 \mathrm{mmol})$ and mesitylene/dioxane $(1: 1 \mathrm{v} / \mathrm{v}, 2 \mathrm{~mL})$. The mixture was sonicated for $10 \mathrm{~min}$ to get a homogenous dispersion. Afterwards, hydrazine ( $8 \mathrm{uL}, 0.15 \mathrm{mmol}$ ) was added and the resultant suspension was briefly sonicated (10-20 s). Subsequently, acetic acid $(6 \mathrm{M}, 0.2 \mathrm{~mL})$ was added and the vial was then sealed and left undisturbed for 3 days at room temperature. The yielded yellow precipitate was collected by centrifugation and washed with anhydrous tetrahydrofuran, anhydrous acetone, and anhydrous dichloromethane, separately. The collected powder was then activated by solvent exchange with anhydrous methanol for 3 times and dried at $120^{\circ} \mathrm{C}$ under vacuum for $12 \mathrm{~h}$ to give a red powder with $78 \%$ isolated yield and a molecular formula of $\left(\mathrm{C}_{9} \mathrm{H}_{6} \mathrm{~N}_{3}\right)_{\mathrm{n}}(\%$ calc/found: C 69.22/69.44, H 3,87/3.80, N 26.91/26.74).

\section{Synthesis of TFP-HZ using room temperature solution-dispersion approach}
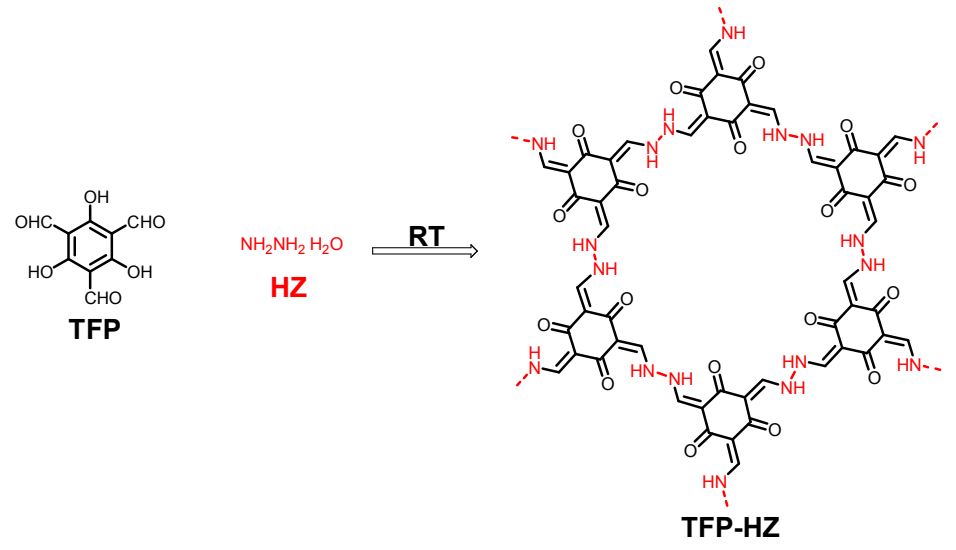

A $10 \mathrm{~mL}$ glass vial was charged with 1,3,5-triformylphloroglucinol (TFP) (21 mg, $0.1 \mathrm{mmol}$ ) and mesitylene/ethanol $(1: 1 \mathrm{v} / \mathrm{v}, 2 \mathrm{~mL})$. The mixture was sonicated for $10 \mathrm{~min}$ to get a homogenous dispersion. Afterwards, hydrazine $(8 \mathrm{uL}, 0.15 \mathrm{mmol})$ was added and the resultant suspension was briefly sonicated (10-20 s). Subsequently, acetic acid (6 M, $0.2 \mathrm{~mL})$ was added and the vial was then sealed and left undisturbed for 3 days at room temperature. The yielded red precipitate was collected by centrifugation and washed with anhydrous tetrahydrofuran, anhydrous acetone, and anhydrous dichloromethane, separately. The collected powder was then activated by solvent exchange with anhydrous methanol for 3 times and dried at $120{ }^{\circ} \mathrm{C}$ under vacuum for $12 \mathrm{~h}$ to give a red powder with $80 \%$ isolated yield and a molecular formula of $\left(\mathrm{C}_{9} \mathrm{H}_{6} \mathrm{~N}_{3} \mathrm{O}_{3}\right)_{\mathrm{n}}(\%$ calc/found: $\mathrm{C} 52.95 / 52.68, \mathrm{H} 2.96 / 2.90, \mathrm{~N} 20.58 / 20.48)$. 
Synthesis of NUS-14 using room temperature solution-dispersion approach

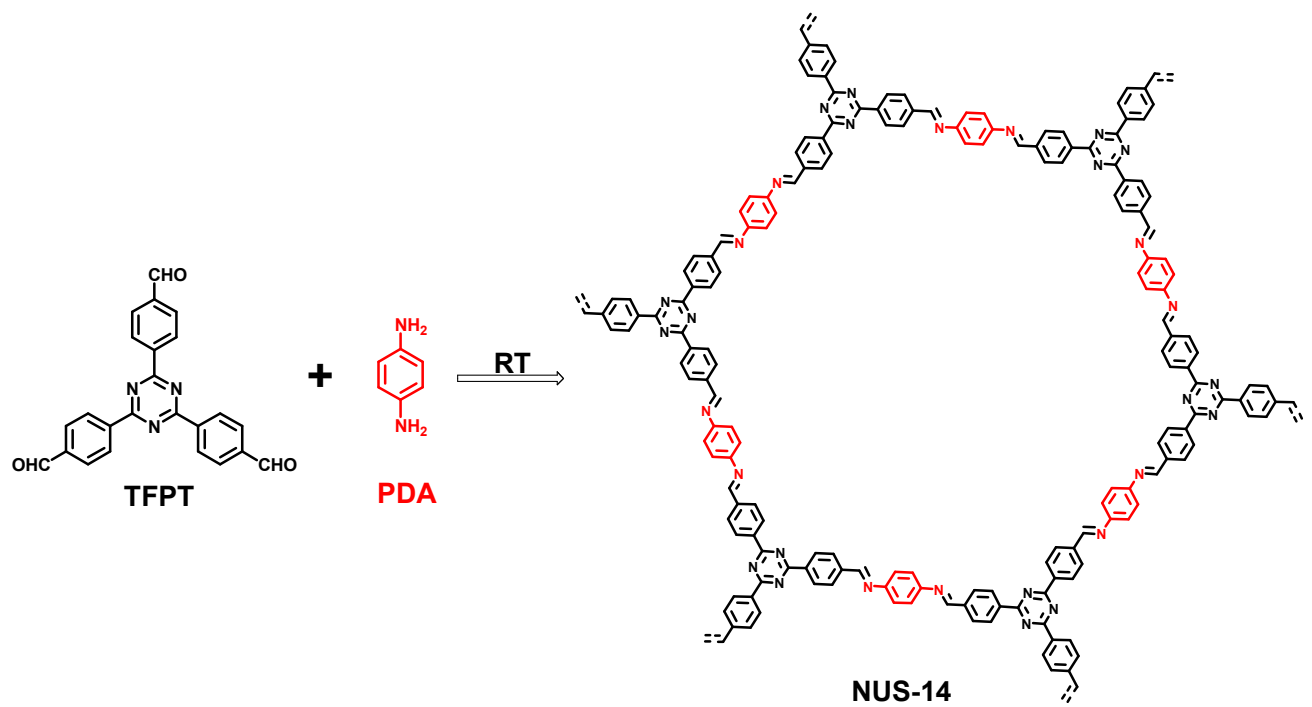

A $10 \mathrm{~mL}$ glass vial was charged with 1,3,5-tris-(4-formyl-phenyl)triazine (TFPT) (17 mg, 0.04 mmol), $p$-phenylenediamine (PDA) $(6.5 \mathrm{mg}, 0.06 \mathrm{mmol})$ and mesitylene/ethanol (1:1 v/v, 2 $\mathrm{mL}$ ). The mixture was sonicated for $10 \mathrm{~min}$ to get a homogeneous dispersion. Subsequently, acetic acid ( $3 \mathrm{M}, 0.2 \mathrm{~mL}$ ) was slowly added. The vial was then sealed and left undisturbed for 3 days at room temperature. The yielded yellow precipitate was collected by centrifugation and washed with anhydrous tetrahydrofuran, anhydrous acetone, and anhydrous dichloromethane, separately. The collected powder was then activated by solvent exchange with anhydrous methanol for 3 times and dried at $120{ }^{\circ} \mathrm{C}$ under vacuum for $12 \mathrm{~h}$ to give a yellow powder with $82 \%$ isolated yield and a molecular formula of $\left(\mathrm{C}_{33} \mathrm{H}_{21} \mathrm{~N}_{6}\right)_{n}(\%$ calc/found: $\mathrm{C} 79.02 / 78.40, \mathrm{H}$ 4.22/4.11, N 16.76/16.90).

\section{Synthesis of NUS-15 using room temperature solution-dispersion approach}

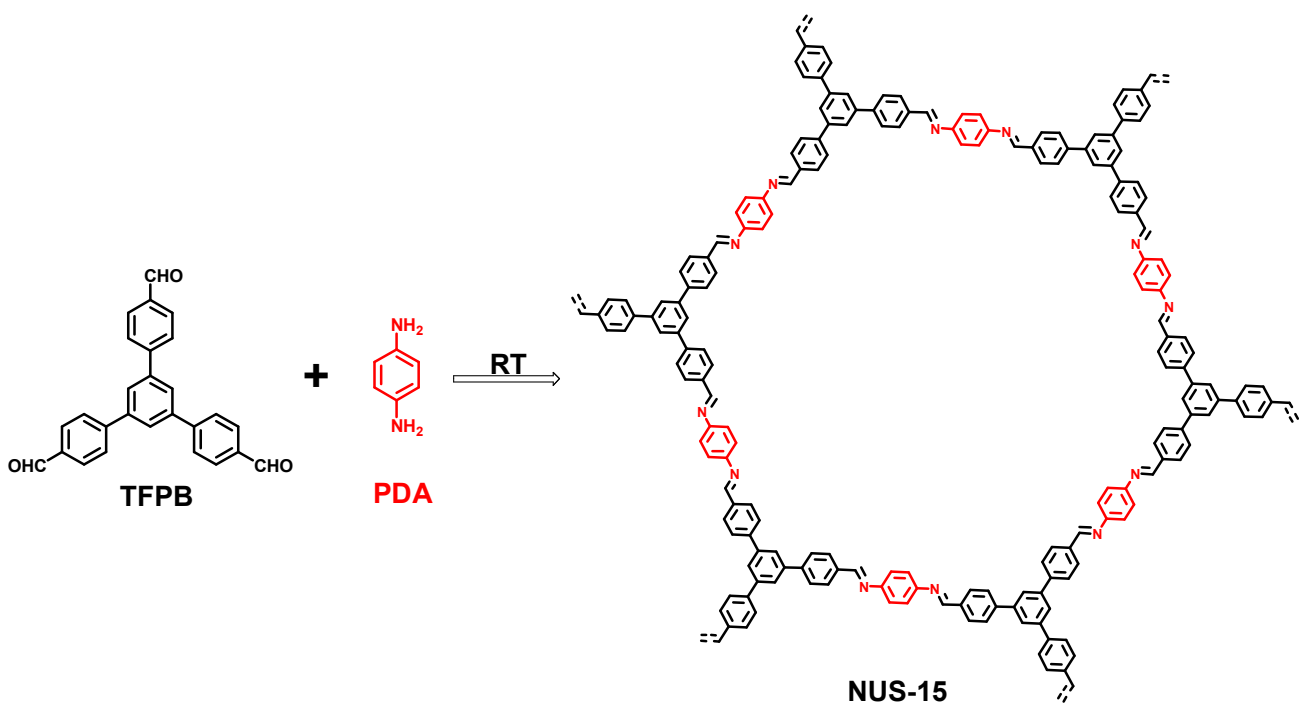


A $10 \mathrm{~mL}$ glass vial was charged with 1,3,5-tris-(4-formyl-phenyl)benzene (TFPB) (17 mg, 0.04 mmol), $p$-phenylenediamine (PDA) $(6.5 \mathrm{mg}, 0.06 \mathrm{mmol})$ and mesitylene/ethanol $(1: 1 \mathrm{v} / \mathrm{v}, 2$ $\mathrm{mL}$ ). The mixture was sonicated for $10 \mathrm{~min}$ to get a homogeneous dispersion. Subsequently, acetic acid ( $3 \mathrm{M}, 0.2 \mathrm{~mL}$ ) was slowly added. The vial was then sealed and left undisturbed for 3 days at room temperature. The yielded yellow precipitate was collected by centrifugation and washed with anhydrous tetrahydrofuran, anhydrous acetone, and anhydrous dichloromethane, separately. The collected powder was then activated by solvent exchange with anhydrous methanol for 3 times and dried at $120^{\circ} \mathrm{C}$ under vacuum for $12 \mathrm{~h}$ to give a yellow powder with $86 \%$ isolated yield and a molecular formula of $\left(\mathrm{C}_{36} \mathrm{H}_{24} \mathrm{~N}_{3}\right)_{\mathrm{n}}(\%$ calc/found: $\mathrm{C} 86.72 / 86.80, \mathrm{H}$ 4.85/4.72, N 8.43/8.36).

\section{Structure Determination}

The structure determination of NUS-14 and NUS-15 started with manual changes of a reported structure ${ }^{1}$ using the Materials Studio Visualizer. ${ }^{2}$ The eclipsed and staggered stacking possibilities were considered for reasons reported in the literature. ${ }^{3}$ The atomic positions and cell sizes were subject to symmetry-constrained geometry optimization runs based on molecular mechanics simulations. These simulations were performed with the Forcite module of Materials Studio, using an algorithm which is a cascade of the steepest descent, adjusted basis set Newton-Raphson, and quasi-Newton methods. The bonded and the short range (van der Waals) non-bonded interactions between atoms were modelled using the Universal Force Field (UFF), as implemented in Forcite. In this force field, bond stretching is described by a harmonic term, angle bending by a three-term Fourier cosine expansion, torsions and inversions by cosine-Fourier expansion terms, and the van der Waals interactions by the Lennard-Jones potential. The long range (electrostatic) non-bonded interactions, which arise due to the presence of partial atomic charges, were modelled using a Coulombic term. An LJ cutoff distance of $18.5 \AA$ was used for all geometry optimization simulations. The Ewald sum method was used to compute the electrostatic interactions. 

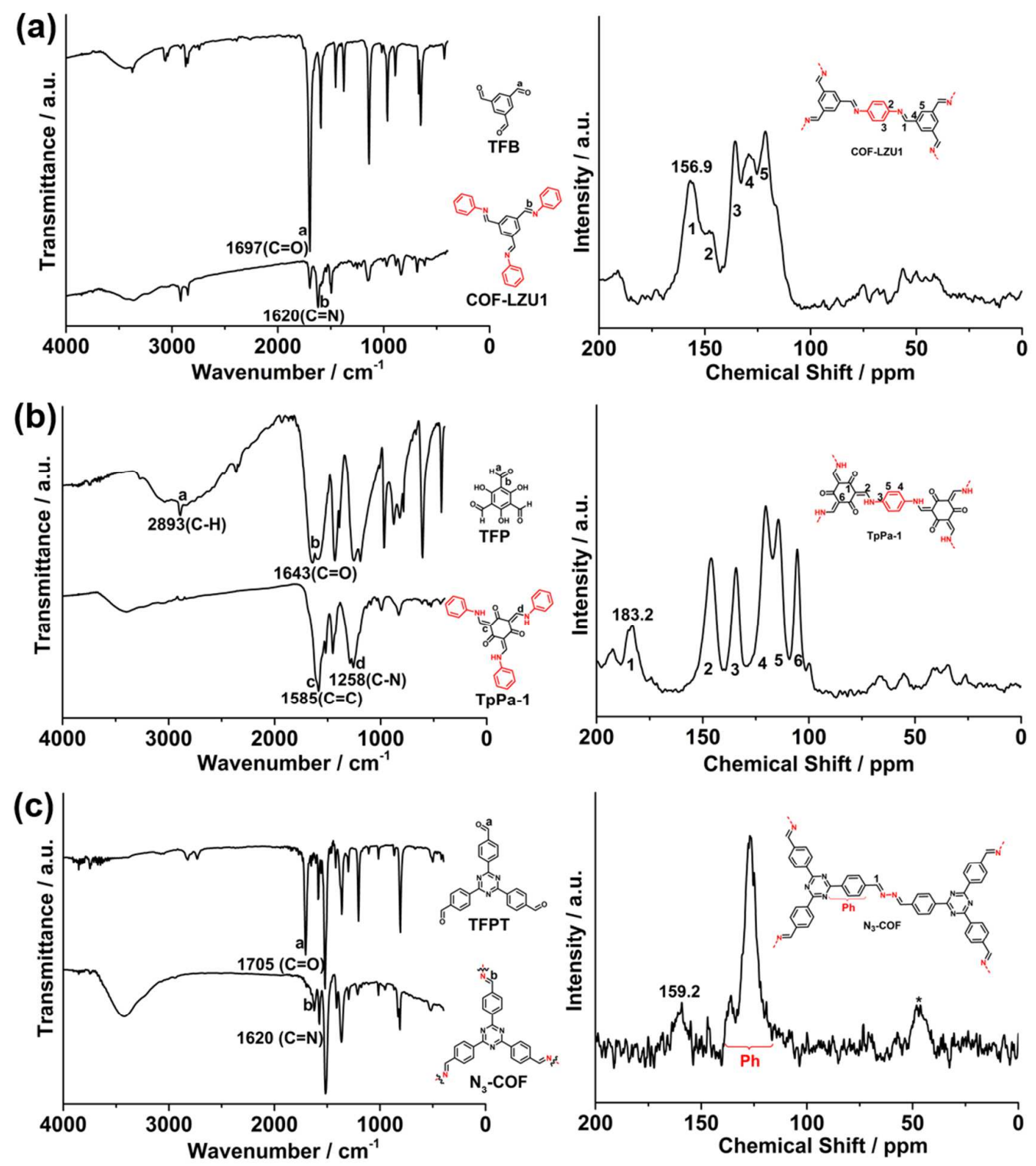

Figure S1. FT-IR (left) and solid-state ${ }^{13} \mathrm{C}$ NMR (right) spectra of COF-LZU1 (SSA) (a), TpPa-1 (SSA) (b), and $\mathrm{N}_{3}-\mathrm{COF}(\mathrm{SSA})$ (c). Asterisks $\left({ }^{*}\right)$ indicate peaks arising from solvent molecules or spinning side bands. 

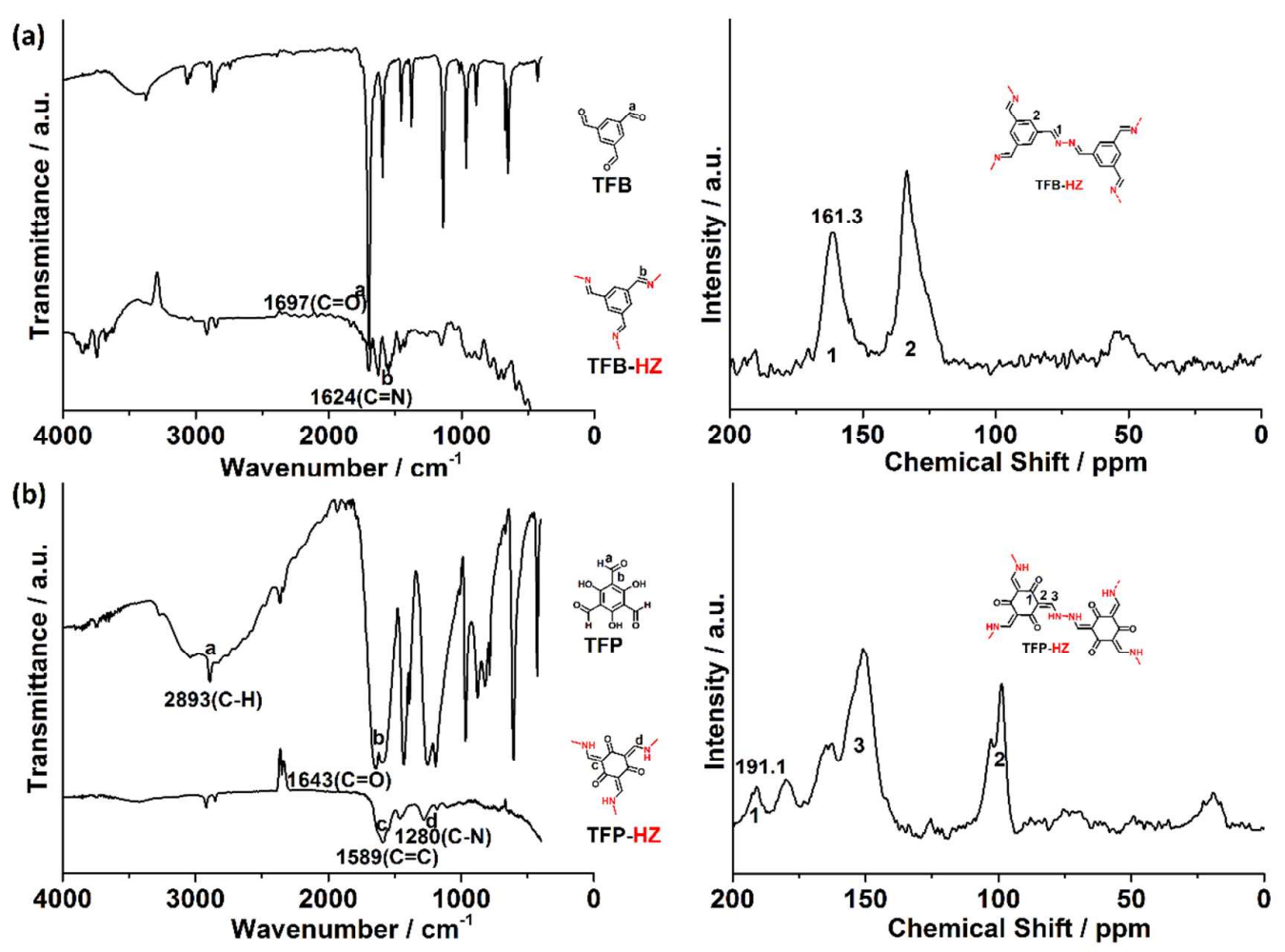

Figure S2. FT-IR (left) and solid-state ${ }^{13} \mathrm{C}$ NMR (right) spectra of TFB-HZ (SSA) (a) and TFP-HZ (SSA) (b). 

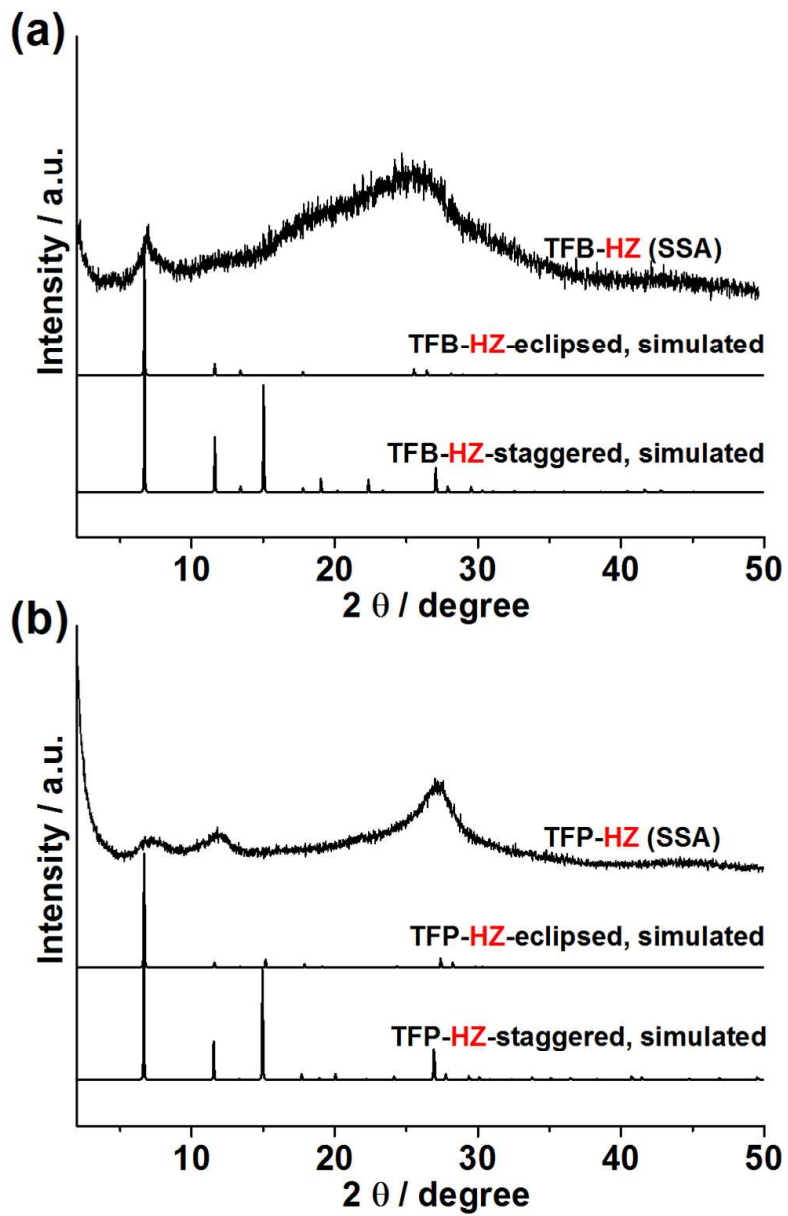

Figure S3. Simulated and experimental PXRD patterns of TFB-HZ (SSA) (a) and TFP-HZ (SSA) (b). 

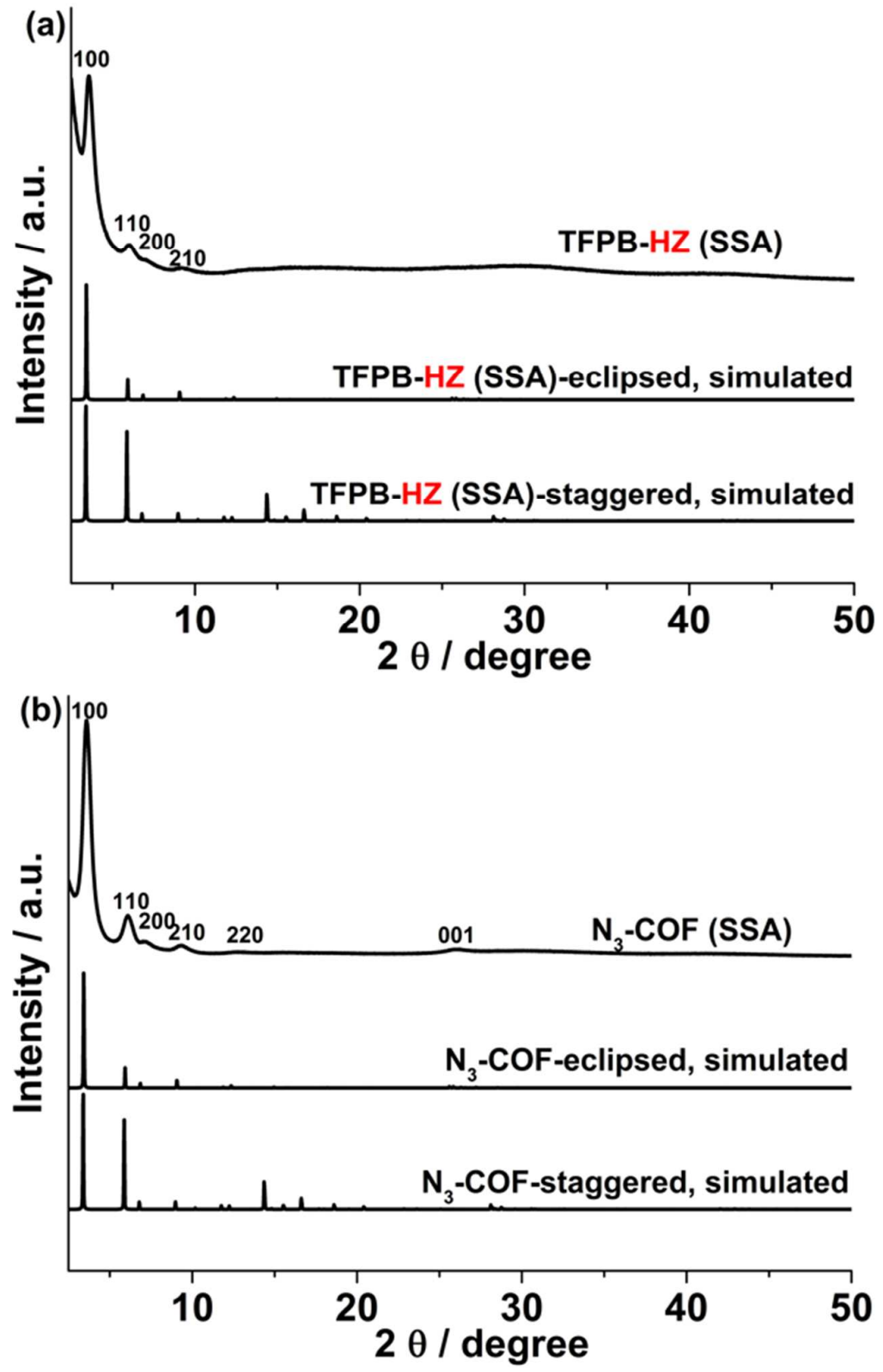

Figure S4. Simulated and experimental PXRD patterns of TFPB-HZ (SSA) (a) and $\mathrm{N}_{3}-\mathrm{COF}$ (SSA) (b). 

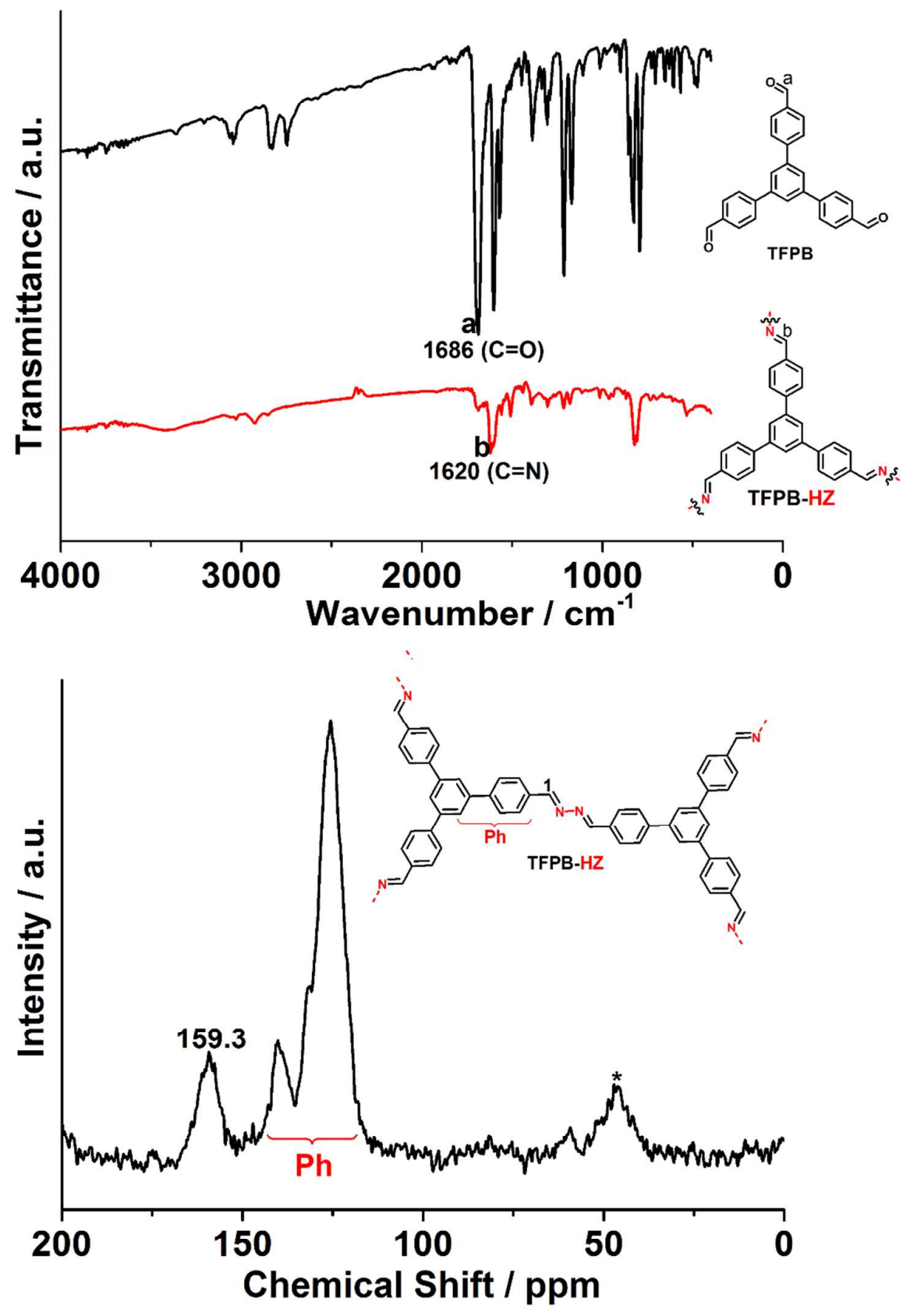

Figure S5. FT-IR (top) and solid-state ${ }^{13} \mathrm{C}$ NMR (bottom) spectra of TFPB-HZ (SSA). Asterisks $\left(^{*}\right.$ ) indicate peaks arising from solvent molecules or spinning side bands. 

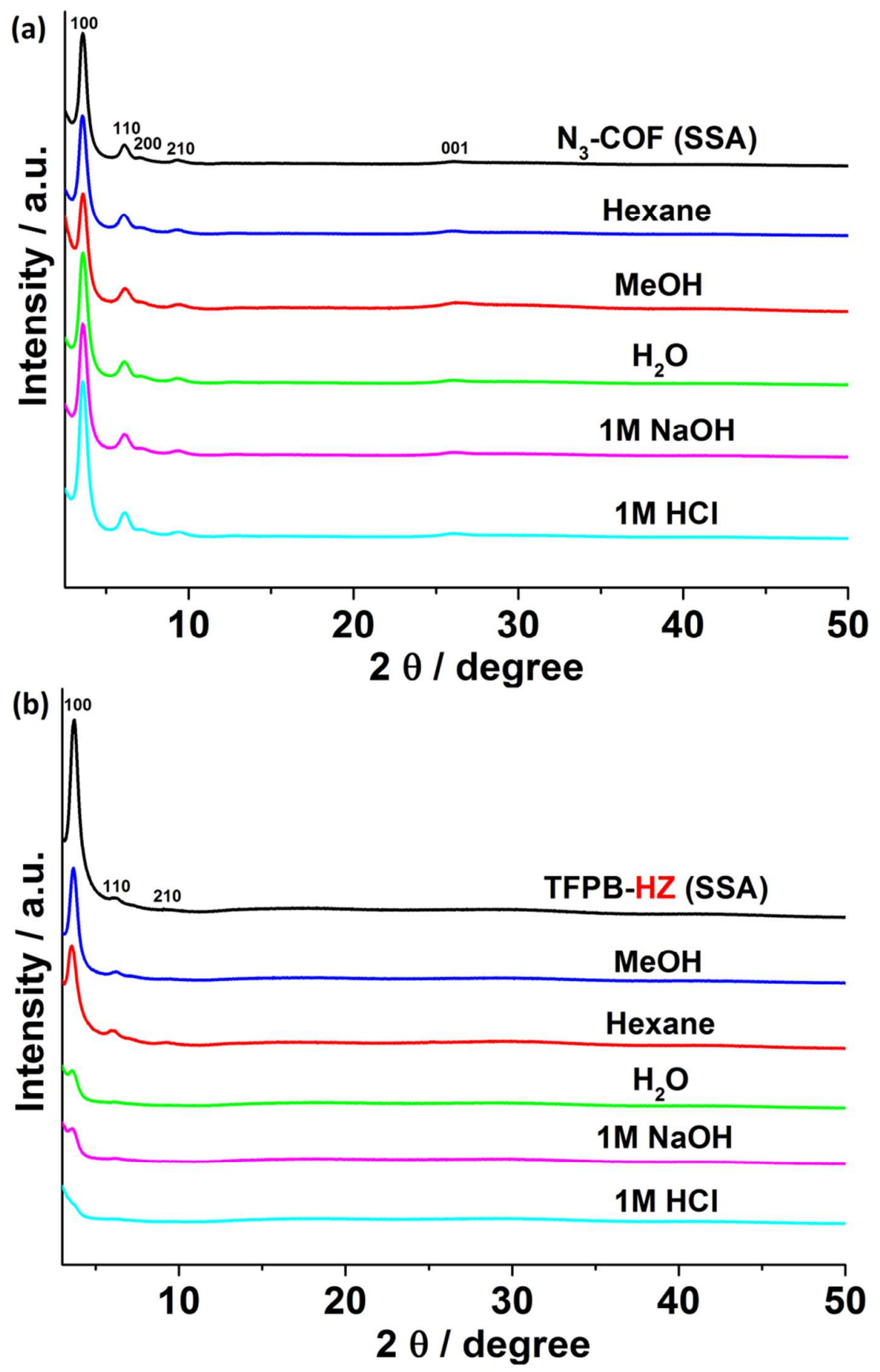

Figure S6. PXRD patterns of fresh $\mathrm{N}_{3}-\mathrm{COF}$ (SSA) (a) and TFPB-HZ (SSA) (b) upon 1-day treatment under different conditions at $298 \mathrm{~K}$. 


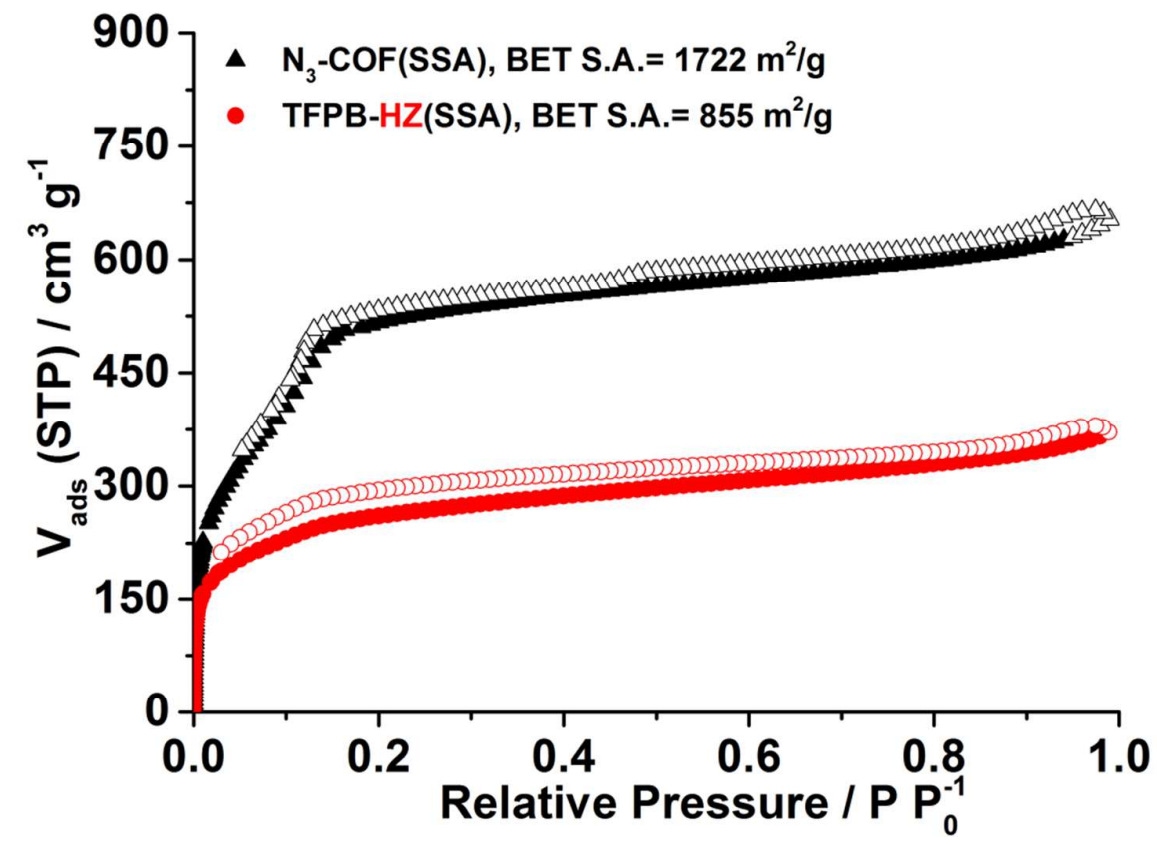

Figure S7. $\mathrm{N}_{2}$ sorption isotherms measured at $77 \mathrm{~K}$ of $\mathrm{N}_{3}-\mathrm{COF}$ (SSA) and TFPB-HZ (SSA). Adsorption, closed; desorption, open. 

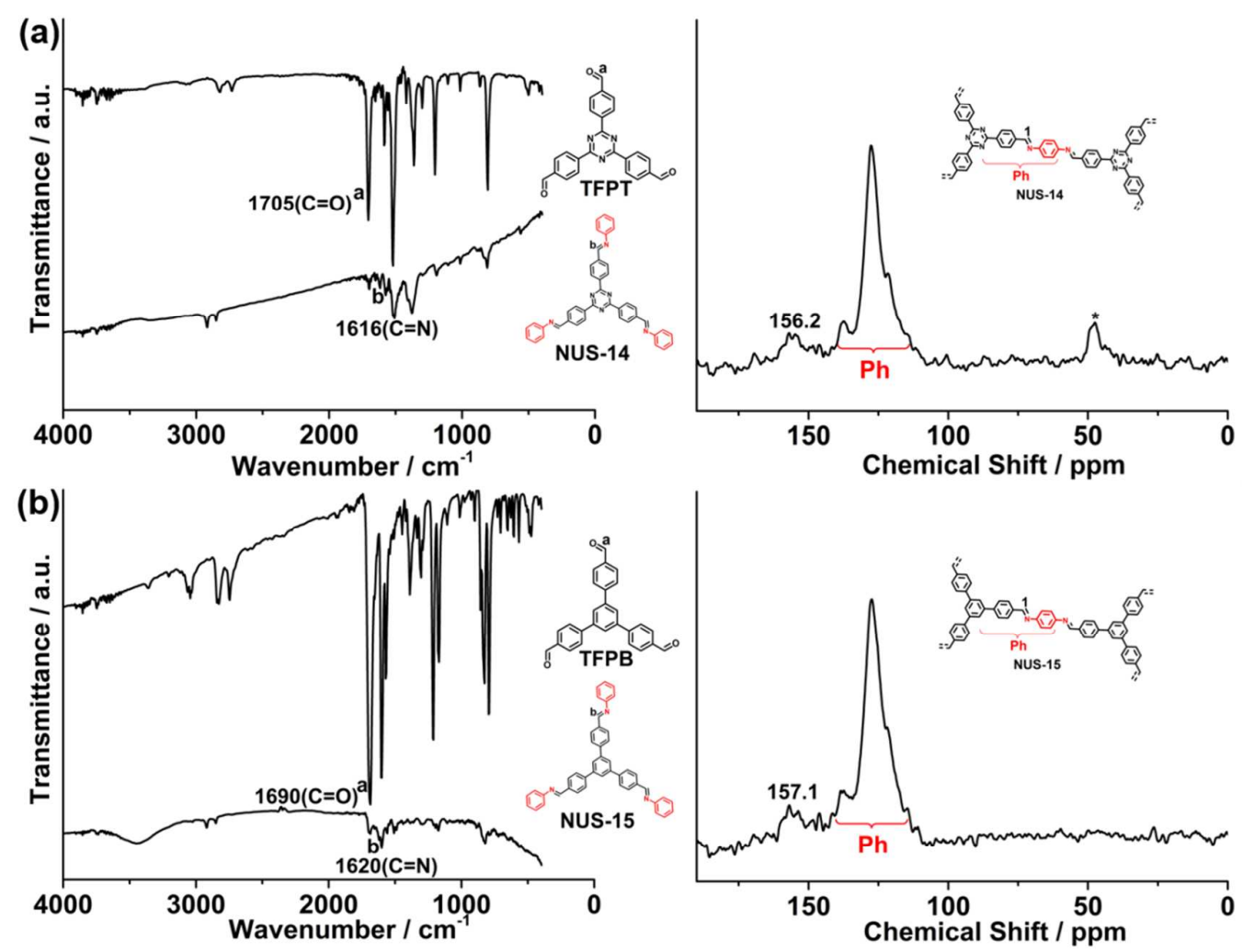

Figure S8. FT-IR (left) and solid-state ${ }^{13} \mathrm{C}$ NMR (right) spectra of NUS-14 (SSA) (a) and NUS-15 (SSA) (b). Asterisks (*) indicate peaks arising from solvent molecules or spinning side bands. 


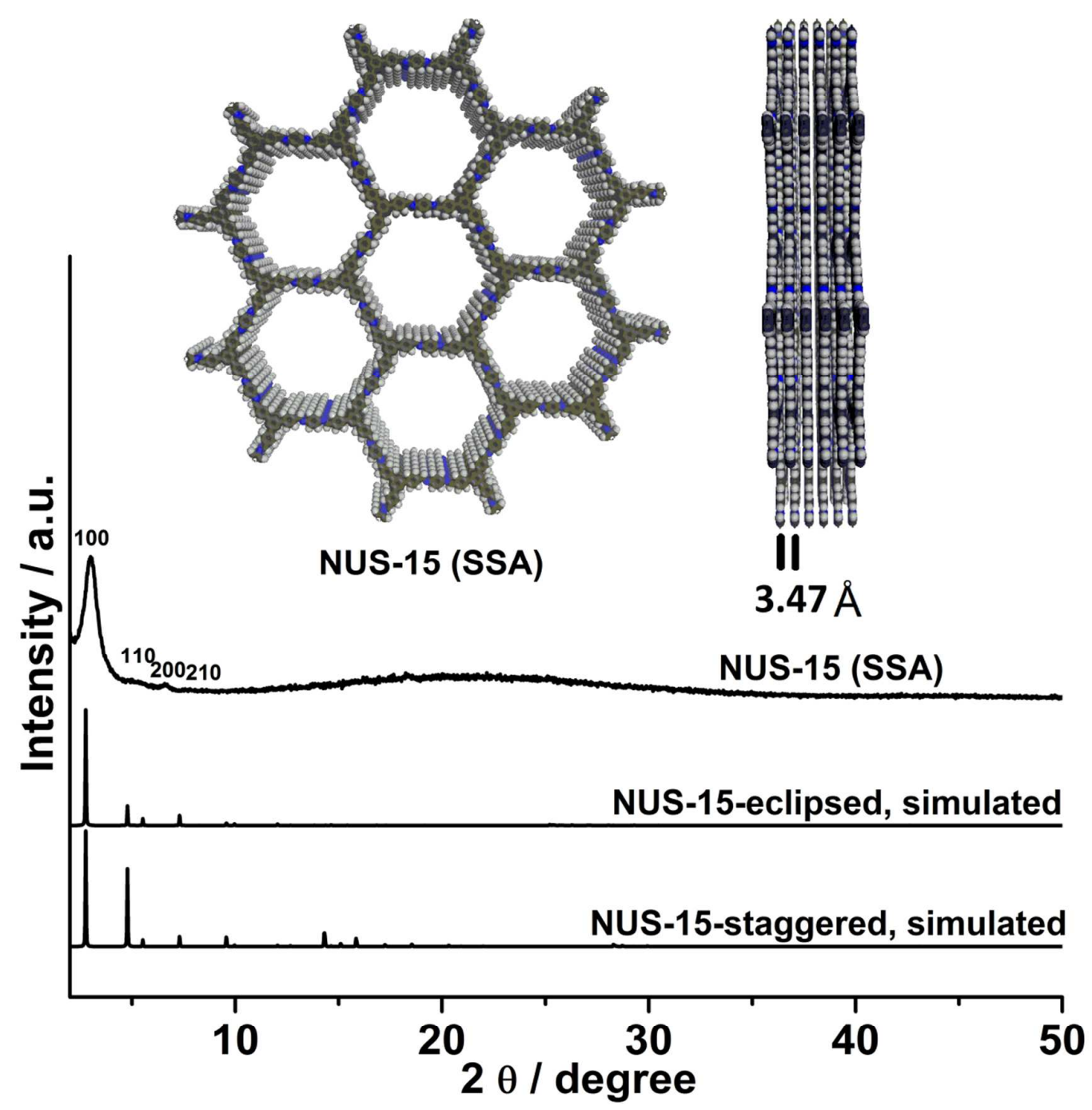

Figure S9. Simulated and experimental PXRD patterns of NUS-15 (SSA) (inset images show the crystal structure of NUS-15 assuming 2D eclipsed stacking viewed through [001] (left) and [100] (right) directions). 


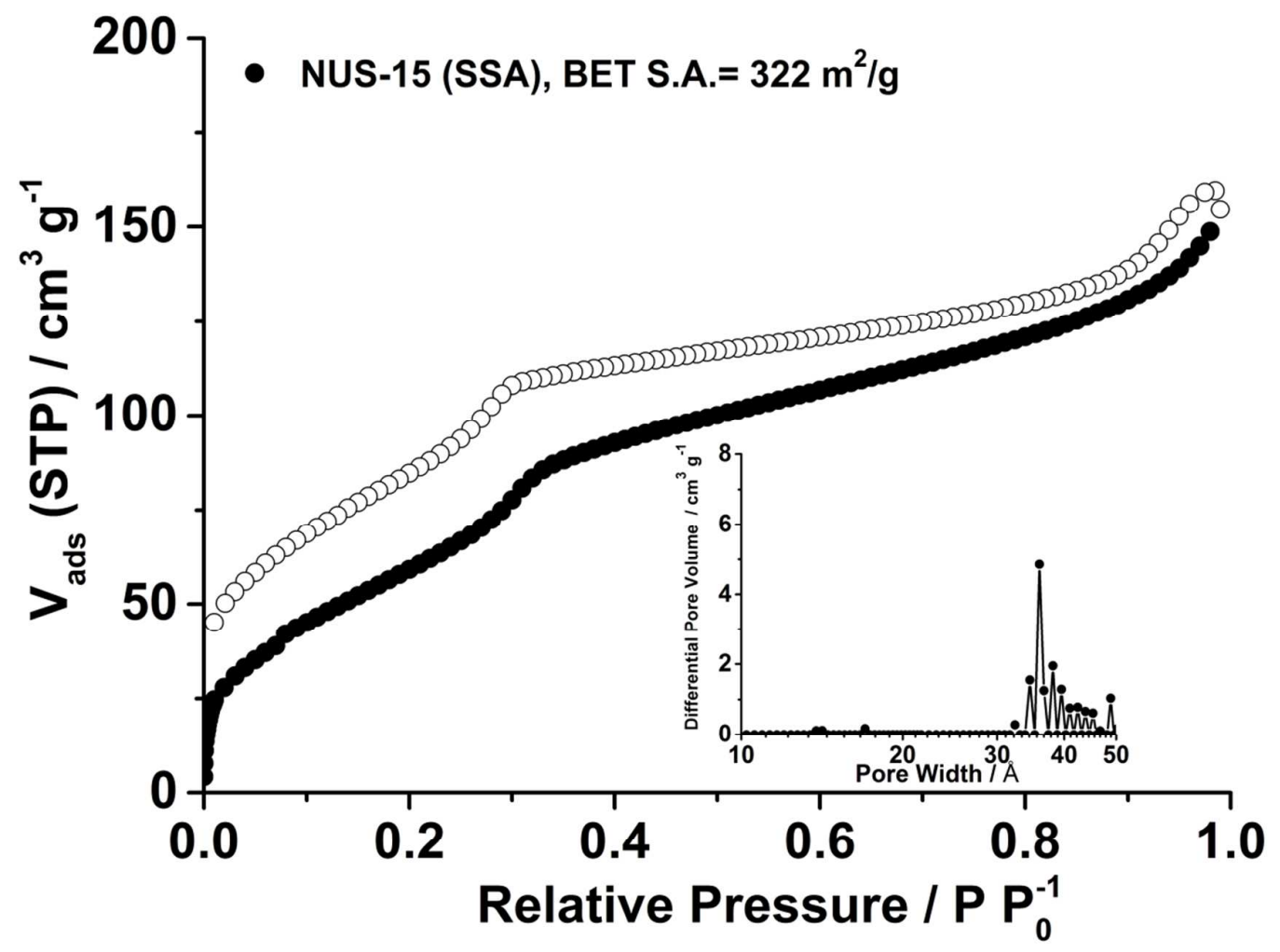

Figure S10. $\mathrm{N}_{2}$ sorption isotherms measured at $77 \mathrm{~K}$ and pore size distribution of NUS-15 (SSA). Adsorption, closed; desorption, open. 

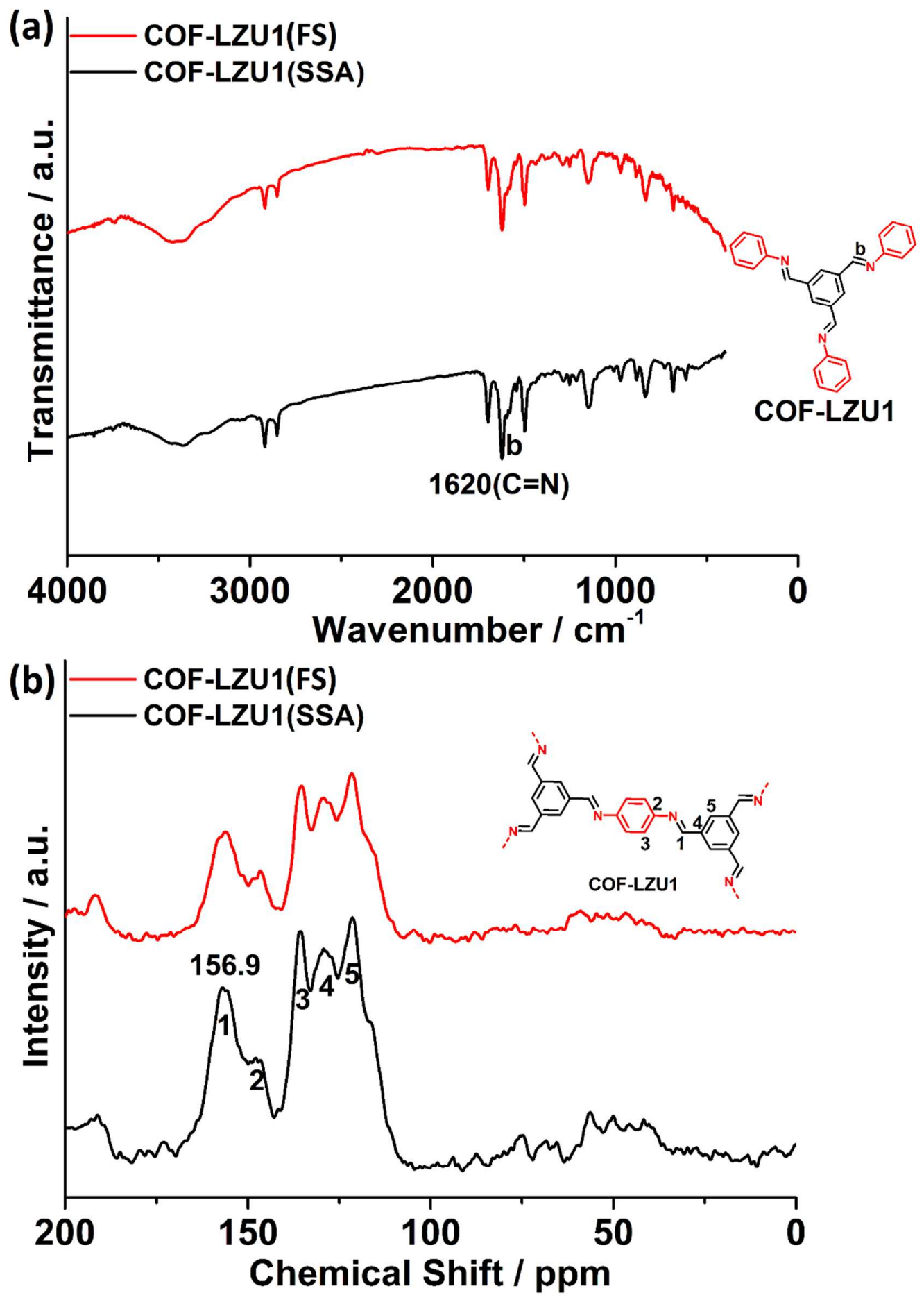

Figure S11. FT-IR (a) and solid-state ${ }^{13}$ C NMR (b) of COF-LZU1 (FS) versus COF-LZU1 (SSA). 


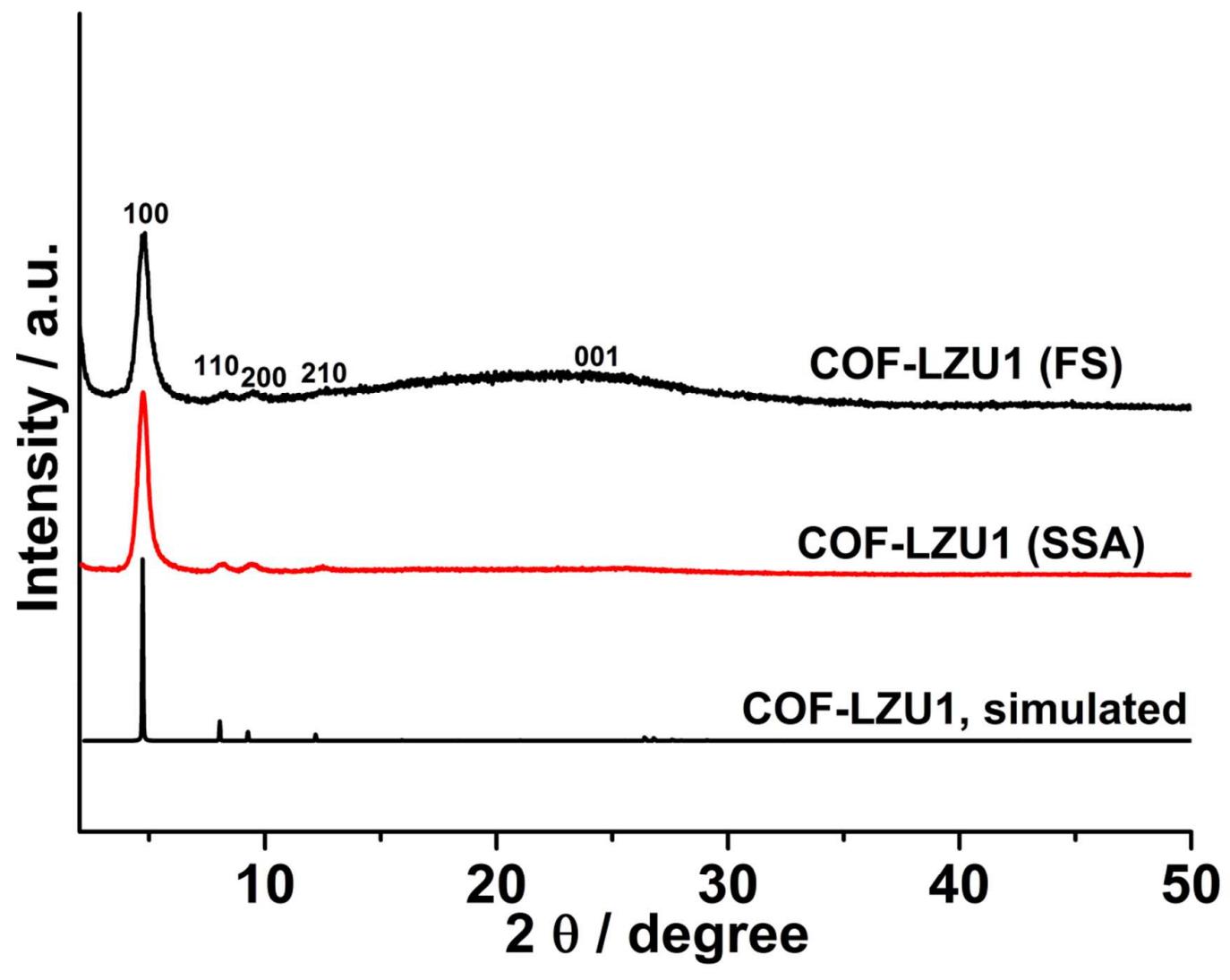

Figure S12. PXRD patterns of COF-LZU1 (FS) versus COF-LZU1 (SSA). 

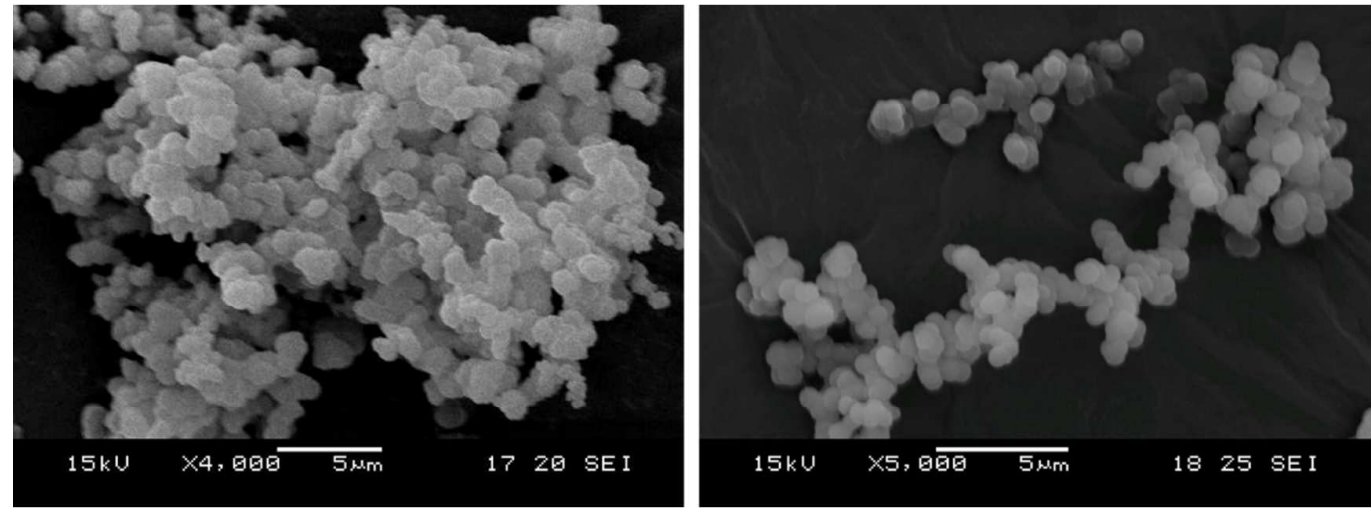

Figure S13. SEM images of COF-LZU1 (FS) (left) versus COF-LZU1 (SSA) (right). 
Table S1. Crystallographic information of modelled NUS-14 (SSA).

Note: the crystallographic information of modelled COF-LZU1, ${ }^{4} \mathrm{TpPa}-1,{ }^{5}$ and $\mathrm{N}_{3}-\mathrm{COF}^{6}$ have been reported in previous studies.

\begin{tabular}{|l|l|}
\hline Parameter & NUS-14 \\
\hline Empirical formula & $\mathrm{C}_{33} \mathrm{H}_{21} \mathrm{~N}_{6}$ \\
\hline $\mathrm{F}_{\mathrm{w}}$ & 501.56 \\
\hline Stacking method & slipped-AA \\
\hline Crystal system & Hexagonal \\
\hline Space group & $P 6 / \mathrm{m}$ \\
\hline$a[\AA]$ & 36.9649 \\
\hline$b[\AA]$ & 36.9649 \\
\hline$c[\AA]$ & 3.5305 \\
\hline$\alpha[\mathrm{deg}]$ & 90 \\
\hline$\beta[\mathrm{deg}]$ & 90 \\
\hline$\gamma[\mathrm{deg}]$ & 120 \\
\hline Interlayer distance $(\AA)$ & 3.53 \\
\hline
\end{tabular}


Table S2. Atom sites for modelled NUS-14 (SSA).

\begin{tabular}{|c|c|c|c|}
\hline Atom site label & Atom site fract $\mathrm{x}$ & Atom site fract $y$ & Atom site fract $\mathrm{z}$ \\
\hline N4 & 0.69273 & -0.68182 & 0.50000 \\
\hline C1 & 0.65104 & -0.70917 & 0.50000 \\
\hline $\mathrm{C} 2$ & 0.58711 & -0.88512 & 0.50000 \\
\hline $\mathrm{H} 2 \mathrm{~A}$ & 0.60811 & -0.89544 & 0.50000 \\
\hline N8 & 0.5457 & -0.91329 & 0.50000 \\
\hline C3 & 0.60236 & -0.84171 & 0.50000 \\
\hline $\mathrm{C} 4$ & 0.63495 & -0.75293 & 0.50000 \\
\hline $\mathrm{C} 5$ & 0.6618 & -0.77001 & 0.50000 \\
\hline H5A & 0.69354 & -0.75082 & 0.50000 \\
\hline C6 & 0.64589 & -0.81346 & 0.50000 \\
\hline H6A & 0.66655 & -0.82427 & 0.50000 \\
\hline $\mathrm{C} 7$ & 0.59134 & -0.78146 & 0.50000 \\
\hline H7A & 0.57056 & -0.77082 & 0.50000 \\
\hline $\mathrm{C} 8$ & 0.57538 & -0.82492 & 0.50000 \\
\hline H8A & 0.54369 & -0.84434 & 0.50000 \\
\hline C9 & 0.52482 & -0.95558 & 0.50000 \\
\hline $\mathrm{C} 10$ & 0.54379 & -0.98063 & 0.50000 \\
\hline H10A & 0.57549 & -0.96732 & 0.50000 \\
\hline C11 & 0.48087 & -0.97547 & 0.50000 \\
\hline H11A & 0.46661 & -0.95784 & 0.50000 \\
\hline
\end{tabular}


Table S3. Crystallographic information of modelled NUS-15 (SSA).

\begin{tabular}{|l|l|}
\hline Parameter & NUS-15 \\
\hline Empirical formula & $\mathrm{C}_{36} \mathrm{H}_{24} \mathrm{~N}_{3}$ \\
\hline $\mathrm{F}_{\mathrm{w}}$ & 498.6 \\
\hline Stacking method & slipped-AA \\
\hline Crystal system & Hexagonal \\
\hline Space group & $P 6 / \mathrm{m}$ \\
\hline$a[\AA]$ & 37.7445 \\
\hline$b[\AA]$ & 37.7445 \\
\hline$c[\AA]$ & 3.4666 \\
\hline$\alpha[$ deg $]$ & 90 \\
\hline$\beta[$ deg $]$ & 90 \\
\hline$\gamma[$ deg $]$ & 120 \\
\hline Interlayer distance $(\AA)$ & 3.47 \\
\hline
\end{tabular}


Table S4. Atom sites for modelled NUS-15 (SSA).

\begin{tabular}{|c|c|c|c|}
\hline Atom site label & Atom site fract $\mathrm{x}$ & Atom site fract y & Atom site fract $\mathrm{z}$ \\
\hline H1 & 0.40755 & 0.71233 & 0.50000 \\
\hline $\mathrm{C} 1$ & 0.69259 & -0.68288 & 0.50000 \\
\hline $\mathrm{C} 2$ & 0.64997 & -0.71008 & 0.50000 \\
\hline $\mathrm{C} 3$ & 0.58224 & -0.88774 & 0.50000 \\
\hline $\mathrm{H} 2$ & 0.60365 & -0.89879 & 0.50000 \\
\hline N1 & 0.54295 & -0.91283 & 0.50000 \\
\hline $\mathrm{C} 4$ & 0.59885 & -0.84305 & 0.50000 \\
\hline $\mathrm{C} 5$ & 0.63214 & -0.7564 & 0.50000 \\
\hline C6 & 0.65753 & -0.77426 & 0.50000 \\
\hline H3 & 0.69034 & -0.75662 & 0.50000 \\
\hline $\mathrm{C} 7$ & 0.64111 & -0.81666 & 0.50000 \\
\hline $\mathrm{H} 4$ & 0.66165 & -0.8289 & 0.50000 \\
\hline $\mathrm{C} 8$ & 0.58928 & -0.78399 & 0.50000 \\
\hline H5 & 0.567 & -0.77423 & 0.50000 \\
\hline C9 & 0.57311 & -0.82635 & 0.50000 \\
\hline H6 & 0.54023 & -0.84628 & 0.50000 \\
\hline $\mathrm{C} 10$ & 0.52219 & -0.95678 & 0.50000 \\
\hline $\mathrm{C} 11$ & 0.54279 & -0.97924 & 0.50000 \\
\hline $\mathrm{H} 7$ & 0.5757 & -0.96439 & 0.50000 \\
\hline $\mathrm{C} 12$ & 0.47942 & -0.97794 & 0.50000 \\
\hline $\mathrm{H} 8$ & 0.46339 & -0.96088 & 0.50000 \\
\hline
\end{tabular}




\section{Reference}

1 Smith, B. J.; Overholts, A. C.; Hwang, N.; Dichtel, W. R. Insight into the crystallization of amorphous imine-linked polymer networks to $2 \mathrm{D}$ covalent organic frameworks. Chem. Commun. 2016, 52, 3690-3693.

2 Accelrys; 5.5 ed.; Accelrys Software, Inc.: San Diego, 2010.

3 Côté, A. P.; Benin, A. I.; Ockwig, N. W.; O'Keeffe, M.; Matzger, A. J.; Yaghi, O. M. Porous, crystalline, covalent organic frameworks. Science 2005, 310, 1166-1170.

4 Ding, S. Y.; Gao, J.; Wang, Q.; Zhang, Y.; Song, W. G.; Su, C. Y.; Wang, W. Construction of covalent organic framework for catalysis: Pd/COF-LZU1 in Suzuki-Miyaura coupling reaction. J. Am. Chem. Soc. 2011, 133, 19816-19822.

5 Kandambeth, S.; Mallick, A.; Lukose, B.; Mane, M. V.; Heine, T.; Banerjee, R. Construction of crystalline 2D covalent organic frameworks with remarkable chemical (acid/base) stability via a combined reversible and irreversible route. J. Am. Chem. Soc. 2012, 134, 19524-19527.

6 Vyas, V. S.; Haase, F.; Stegbauer, L.; Savasci, G.; Podjaski, F.; Ochsenfeld, C.; Lotsch, B. V. A tunable azine covalent organic framework platform for visible light-induced hydrogen generation. Nat. Commun. 2015, 6, 8508 . 